\title{
Cerebral venous and sinus thrombosis diagnosis: preliminary study of clinical picture and D-dimer concentration correlation
}

\author{
Izabela Domitrz ${ }^{1}$, Artur Sadowski ${ }^{1}$, Wojciech Domitrz ${ }^{2}$ Jan Kochanowski ${ }^{1}$ \\ ${ }^{1}$ Department of Neurology, Faculty of Medical Sciences, Medical University of Warsaw, Warsaw, Poland \\ ${ }^{2}$ Faculty of Mathematics and Information Science, Warsaw University of Technology, Warsaw, Poland
}

\begin{abstract}
Aim of the study. We investigated whether D-dimer (DD) concentration is elevated in cerebral venous and sinus thrombosis (CVST), as has been reported in the literature.

Clinical rationale for the study. CVST is a disease with variable clinical presentations and a challenging diagnosis. We looked into whether D-dimer concentration might be an indicator of CVST, and the need for neuroimaging tests correlated with clinical factors. Materials and methods. We included all consecutive patients (mean age 41.6 years) with CVST treated in our neurology department from 2014 to 2018 whose DD levels had been measured. DD concentrations were categorised as normal $(\leq 0.5 \mu \mathrm{g} / \mathrm{ml})$ or elevated ( $>0.5 \mu \mathrm{g} / \mathrm{ml}$ ). Appropriate imaging confirmed the diagnosis of CVST. The results were compared to those of a control group consisting of 22 age- and sex-matched patients (mean age 40 years) with a diagnosis of primary headache (tension type or migraine) hospitalised to exclude secondary causes.

Results. In 20 patients in the CVST study group, median level of DD was $1.0+0.57 \mu \mathrm{g} / \mathrm{ml}$ (range $0.19-2.45 \mu \mathrm{g} / \mathrm{ml}$ ), compared to the control group's mean DD level of $0.50+0.45 \mu \mathrm{g} / \mathrm{ml}$ (range $0.15-1.73 \mu \mathrm{g} / \mathrm{ml}$ ), with $p<0.005$. Higher DD levels were associated with complications of the disease and fatal course $(p<0.005)$. One female and one male patient died because of CVST with DD levels of (respectively) 2.45 and $1.80 \mu \mathrm{g} / \mathrm{ml}$ - the two highest concentrations in our study group.

Conclusions and clinical implications. DD concentration, especially in headache patients, may be a factor to predict CVST and an indicator for further diagnostic procedures with venography. But in clinical practice, low levels of DD cannot be taken to exclude CVST.

Key words: $\mathrm{d}$-dimer, cerebral venous and sinus thrombosis, number of venous sinuses involvement, symptoms duration

(Neurol Neurochir Pol 2020; 54 (1):66-72)
\end{abstract}

\section{Introduction}

Cerebral venous and sinus thrombosis (CVST) is a rare cause of stroke which affects typically young adults, mainly females [1]. The incidence of CVST is probably about $3-4$ cases per million in the general population [1], but there is no reliable epidemiological data on this topic. It can have many overlapping symptoms in the acute, subacute or chronic phases, with a lot of varying clinical manifestations. So, a confirmed CVST diagnosis presents many challenges in everyday clinical practice. Known risk factors for CVST include pregnancy, recent childbirth, the use of oral contraceptives, prothrombotic states, coagulation disturbances, infections, dehydration, emaciation, and cancer, and if present these can make the diagnosis easier. In some cases however, no risk factors are recognised, and this can prolong the diagnostic process. It is unclear whether D-dimer (DD) levels reflect clinical presentation, radiological features of CVST involvement, and outcome in this disease. There are some studies showing that DD concentrations are elevated in CVST [9]. DD measurement is useful in patients suspected of CVST, and patients with elevated levels should be urgently sent for venography of CT or MR (depending

Address for correspondence: Izabela Domitrz, Department of Neurology, 2nd Faculty of Medicine, Medical University of Warsaw, Cegłowska 80 Str.,

01-809 Warsaw, Poland, e-mail: izabela.domitrz@wum.edu.pl 
on their resolution and sensitivity in a hospital). But on the other hand, in clinical practice, low levels of DD cannot rule out the disease in patients with subacute or chronic disease [10], although Hiltunen at al. [10] concluded that high DD levels correlate with greater thrombus extension and acute onset of symptoms.

In the study by Misra et al. [11], 26 patients with CVST had flight MR venography. In this study, DD was estimated and the results were positive in 20 patients and correlated with the duration of symptoms but not with the extent of sinus thrombosis and the outcome of the disease [11]. The authors concluded that DD is a useful parameter in patients suspected of CVST, and they stated that all patients with positive DD test results should be urgently sent for MR imaging. In another prospective study [12], 233 CVST-suspected patients were enrolled. 34 cases of CVST were confirmed using imaging modalities, whereas the other 199 cases served as mimic controls. DD and fibrinogen levels of all patients and controls were measured before imaging and treatment. In the CVST patients, more than $94 \%$ had DD elevation. Additionally, the authors claimed that DD may serve as an important screening tool to determine the urgency of obtaining magnetic resonance imaging/magnetic resonance venography or digital subtraction angiography in patients presenting with clinical symptoms that are suspected of CVST, because DD might predict CVST. It is very important to make the proper diagnosis without delay because recent improvements in treatment, implemented early in the disease course, have resulted in better outcomes [13-16].

We were interested in confirming whether DD concentrations in our population were indeed elevated in CVST as reported in those studies, and whether DD might be a factor predicting the need for neuroimaging tests such as venography of CT (veno-CT) or MR correlated with clinical factors.

\section{Clinical rationale for the study}

It is known that DD levels correlate with deep vein thrombosis (DVT) [2, 3] and pulmonary thromboembolism [4-6], and that they might be a marker of CVST. DD levels are closely, strongly and positively related to the clinical status of DVT $[2,7]$ and some findings have suggested that a high plasma DD level during the course of acute stroke (initially normal) can help detect DVT on duplex venous ultrasonography [8]. Proving that DD concentrations also correlate with the risk of CVST would have important clinical usefulness.

\section{Materials and methods}

\section{Study design}

We included in the study all consecutive patients with CVST diagnosis treated in our hospital from 2014 to June 2018. The study group consisted of 20 patients: 15 female (75\%) and five male (25\%), mean age 42 years (range $20-84$ ). Before the disease all patients had 0 in modified Rankin
Scale. Demographic characteristics with involved sinuses and DD levels are presented in Table 1 . Our age- $(\mathrm{p}=0.7)$ and sex- $(p=0.8)$ matched control group consisted of 22 patients with primary headache (tension type or migraine), mean age 40 years (range 19-79) hospitalised because of headache with the exclusion of any serious neurological disease. The control group consisted of 16 females (73\%) and six males (27\%). Controls were recruited from our clinic, after performing angiography (CT or MR) and measuring DD level (mean 0.50 $\pm 0.45 \mu \mathrm{g} / \mathrm{ml} ; \min .=0.15 ; \max .=1.73 \mu \mathrm{g} / \mathrm{ml}$ ). All patients with a DD level higher than $0.5 \mu \mathrm{g} / \mathrm{ml}$ had a cause for it: four had a urinary tract infection, one had prostate cancer, and one was pregnant. All the individuals in our study groups (control and CVST) were Caucasian. Mean age for study groups was not significantly different ( $\mathrm{t}$-Student test $-\mathrm{t}=0.32 ; \mathrm{p}=0.75$ ). Sex of patients for study groups was also not significantly different (Pearson $\chi^{2}=0.028 ; \mathrm{p}=0.87$ ).

\section{Patients with CVST diagnosis}

DD levels measured before initiation of anticoagulant treatment (if needed) were, in mean level in the study group, $1.0 \pm 0.57 \mu \mathrm{g} / \mathrm{ml}$. Lilliefors test $(\mathrm{p}>0.2)$ and Shapiro-Wilk test $(\mathrm{W}=0.96 ; \mathrm{p}=0.52)$ showed that $\mathrm{DD}$ was normally distributed in the study group. DD was categorised as low $(\leq 0.5 \mu \mathrm{g} / \mathrm{ml})$, or increased $(>0.5 \mu \mathrm{g} / \mathrm{ml}$; and in this range high, when $>2.0 \mu \mathrm{g} / \mathrm{ml}$ ). Based on delay from symptoms onset to hospital presentation, the mode of onset was categorised as acute ( $<3$ days), subacute (4-7 days), or chronic ( $>$ days). $9 / 20(45 \%)$ of our patients were categorised as acute ones, eight (40\%) as subacute, one (5\%) as chronic, and two (10\%) as unknown (because of unconsciousness and insufficient medical information).

20 cases of CVST were diagnosed within this period in our hospital with veno-CT (Fig.1 A, B, C) (performed within two hours of notification to the hospital emergency department and from two hours of symptoms onset to 60 days in the case of one patient) and were consecutively enrolled in this study. The number and the type of sinuses involved are presented in Table 1. CVST patients who had a plasma DD test (20 cases) were included and divided into two groups: the elevated DD group (>0.5 $\mu \mathrm{g} / \mathrm{ml}$ ) comprised $15(75 \%)$ patients, and the normal DD group $(\leq 0.5 \mu \mathrm{g} / \mathrm{ml})$ consisted of five $(25 \%)$ patients. Only one female patient had high levels of D-dimer (more than $2.00 \mu \mathrm{g} / \mathrm{ml})-2.45 \mu \mathrm{g} / \mathrm{ml}$ with a fatal course comprising stroke (Fig. 2 A, B, C, D) and death. The next highest DD level was $1.8 \mu \mathrm{g} / \mathrm{ml}$ in the case of a male patient, also with a fatal course of the disease. Clinical data such as: time of symptoms onset, type of symptoms during admission to emergency department, other symptoms and complications that appeared during hospitalisation, course of CVST, and prior risk factors are set out in Table 2.

It is important to emphasise that $17 / 20(85 \%)$ of our CVST patients complained of headache, 2/20 (10\%) were asymptomatic, and 1/20 (5\%) lost consciousness. 

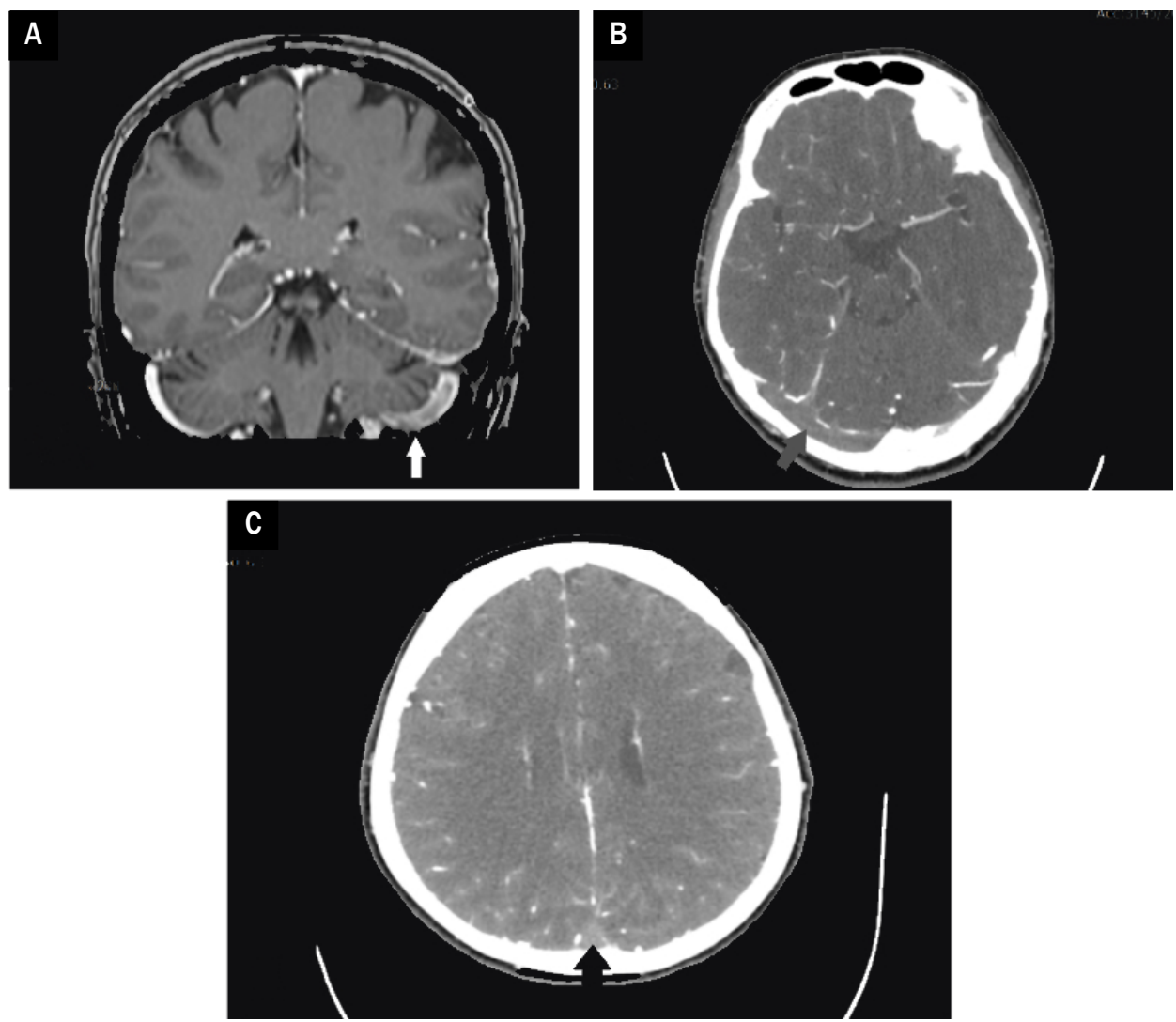

Figure 1. Direct visualisation of thrombosis on vascular imaging. A. Angio-MR with thrombus in left sigmoid sinus. B. Angio-CT with thrombosis of right transverse sinus. C. Angio-CT with thrombus in superior sagittal sinus

Complications of CVST included $3 / 20(15 \%)$ ischaemic stroke, $3 / 20(15 \%)$ subarachnoid haemorrhage (SAH), $1 / 20(5 \%)$ haemorrhagic stroke, and 2/20 (10\%) seizures. In $6 / 20$ (30\%), focal neurological symptoms were recognised. The patients were compared in terms of demographic data, clinical manifestations, and laboratory and imaging data, using inferential statistical methods. Demographic characteristics of the control group with type of neuroimaging performed, DD levels and risk factors are set out in Table 3. All patients with CVST were treated with low molecular weight heparin given subcutaneously. In cases with favourable outcomes, after about two weeks the treatment was changed for oral vitamin $\mathrm{K}$ antagonists.

\section{Statistical analysis}

Statistical analysis was carried out using Statistica 13.3. P-values of $<0.05$ were considered statistically significant. Normality of distribution in the study and control groups was performed using the Lilliefors Test and the Shapiro-Wilk Test. DD levels were compared across the study and control groups performing t-tests and non-parametrical tests: the Mann-Whitney U Test and Kolmogorov-Smirnov Test. Variances were checked using Levene's Test.

\section{Results}

The t-test showed that the CVST group (20 cases) had significantly higher levels of DD $(\mathrm{t}=3.49 ; \mathrm{p}=0.0001)$ compared to the control group (22 cases) (Fig.3), and the variances were not significantly different (F-test: $\mathrm{F}=1.62$; $\mathrm{p}=0.28$; Levene's Test: $\mathrm{F}(1.40)=1.25 ; \mathrm{p}=0.27)$. Since DD was not normally distributed in the control group, non-parametric tests were performed too. Mann-Whitney U Test $(p=0.001)$ and Kolmogorov-Smirnov Test $(p<0.005)$ showed that distributions of DD in the study and control groups were different.

Patients with elevated DD levels were more likely to have a more severe course of the disease with serious complications such as stroke, subarachnoid haemorrhage and seizures ( $\mathrm{t}$-test: $\mathrm{t}=3.43 ; \mathrm{p}=0.003$ and $\mathrm{t}=2.98 ; \mathrm{p}=0.008$, respectively); the variances were not significantly different (F-test: $\mathrm{F}=1.25$; $\mathrm{p}=0.68$; Levene's test: $\mathrm{F}(1.18)=0.003 ; \mathrm{p}=0.95)$.

There was no significant difference in DD level between the groups with an earlier time of onset, shorter symptoms duration, more risk factors, and higher number of affected venous sinuses $(p>0.05)$, probably due to the small number of patients in the study group. 
Table 1. Data of study group

\begin{tabular}{|c|c|c|c|c|c|c|}
\hline & Age & Sex & $\mathrm{DD}, \mu \mathrm{g} / \mathrm{ml}$ & Involved sinuses & Number of involved sinuses & Course of the CVST \\
\hline 1. & 29 & $\mathrm{~F}$ & 1.55 & $\begin{array}{l}\text { Sigmoid; } \\
\text { Right transverse; } \\
\text { Inferior sagittal; } \\
\text { Straight }\end{array}$ & 4 & Full recovery \\
\hline 2. & 21 & M & 1.60 & $\begin{array}{l}\text { Superior sagittal; } \\
\text { Right transverse and sigmoid }\end{array}$ & 3 & Full recovery \\
\hline 3. & 67 & M & 1.80 & $\begin{array}{l}\text { Superior sagittal; } \\
\text { Right transverse }\end{array}$ & 2 & Fatal: death \\
\hline 4. & 48 & $\mathrm{~F}$ & 0.32 & Left transverse & 1 & Full recovery \\
\hline 5. & 34 & M & 0.28 & Right transverse & 1 & Full recovery \\
\hline 6. & 42 & $\mathrm{~F}$ & 1.02 & $\begin{array}{l}\text { Superior sagittal; } \\
\text { Right transverse }\end{array}$ & 2 & Full recovery \\
\hline 7. & 38 & $\mathrm{~F}$ & 0.19 & Right transverse and sigmoid & 2 & Full recovery \\
\hline 8. & 84 & M & 1.19 & Left transverse & 1 & Full recovery \\
\hline 9. & 26 & $\mathrm{~F}$ & 0.87 & $\begin{array}{l}\text { Superior sagittal; } \\
\text { Right transverse and sigmoid }\end{array}$ & 3 & Full recovery \\
\hline 10. & 29 & M & 1.35 & $\begin{array}{l}\text { Superior sagittal; } \\
\text { Right transverse and sigmoid }\end{array}$ & 3 & Full recovery \\
\hline 11. & 20 & $\mathrm{~F}$ & 0.37 & Right transverse & 1 & Full recovery \\
\hline 12. & 29 & $\mathrm{~F}$ & 2.45 & $\begin{array}{l}\text { Superior sagittal; } \\
\text { Venous stroke }\end{array}$ & 1 & Fatal: stroke and death \\
\hline 13. & 65 & $\mathrm{~F}$ & 0.45 & Right sigmoid & 1 & Full recovery \\
\hline 14. & 27 & $\mathrm{~F}$ & 1.40 & $\begin{array}{l}\text { Superior sagittal; } \\
\text { Right transverse and sigmoid }\end{array}$ & 3 & Full recovery \\
\hline 15. & 32 & $\mathrm{~F}$ & 0.95 & Left transverse and sigmoid & 2 & Full recovery \\
\hline 16. & 30 & $\mathrm{~F}$ & 1.55 & $\begin{array}{l}\text { Superior sagittal; } \\
\text { Left transverse and sigmoid; Straight sinus; } \\
\text { Great cerebral vein; } \\
\text { Cavernous sinuses }\end{array}$ & 5 & Full recovery \\
\hline 17. & 62 & $\mathrm{~F}$ & 1.00 & Left transverse and sigmoid & 2 & Full recovery \\
\hline 18. & 43 & $\mathrm{~F}$ & 1.10 & $\begin{array}{l}\text { Superior sagittal; } \\
\text { Right transverse and sigmoid }\end{array}$ & 3 & Full recovery \\
\hline 19. & 67 & $\mathrm{~F}$ & 1.01 & Right sigmoid & 1 & Full recovery \\
\hline 20. & 40 & $\mathrm{~F}$ & 0.79 & Straight & 1 & Full recovery \\
\hline
\end{tabular}

CVT - cerebral venous and sinus thrombosis; $\mathrm{DD}-\mathrm{D}$-dimer; $\mathrm{F}-$ female; $\mathrm{M}$ - male

\section{Discussion and clinical implications}

Our study found that DD is elevated in patients with a CVST diagnosis, as other authors have reported [9]. Additionally, we looked into whether an elevated DD concentration is related to a worse course of the disease and its complications. We did not confirm a statistical correlation between a higher DD level and an earlier time of onset, shorter symptoms duration, more risk factors, and number of affected venous sinuses.
We acknowledge that our study is limited because of the small number of patients in the study group, but this work is a preliminary one and our patients were consecutively hospitalised in our department from 2014 to June 2018. Thus, probably the correlations are negative due to the small number of patients in the study group. It is worth noting that $25 \%$ of our CVST patients had a normal level of D-dimer. In clinical practice, low levels of DD cannot rule out CVST in patients with (especially) subacute or chronic disease. High DD levels 

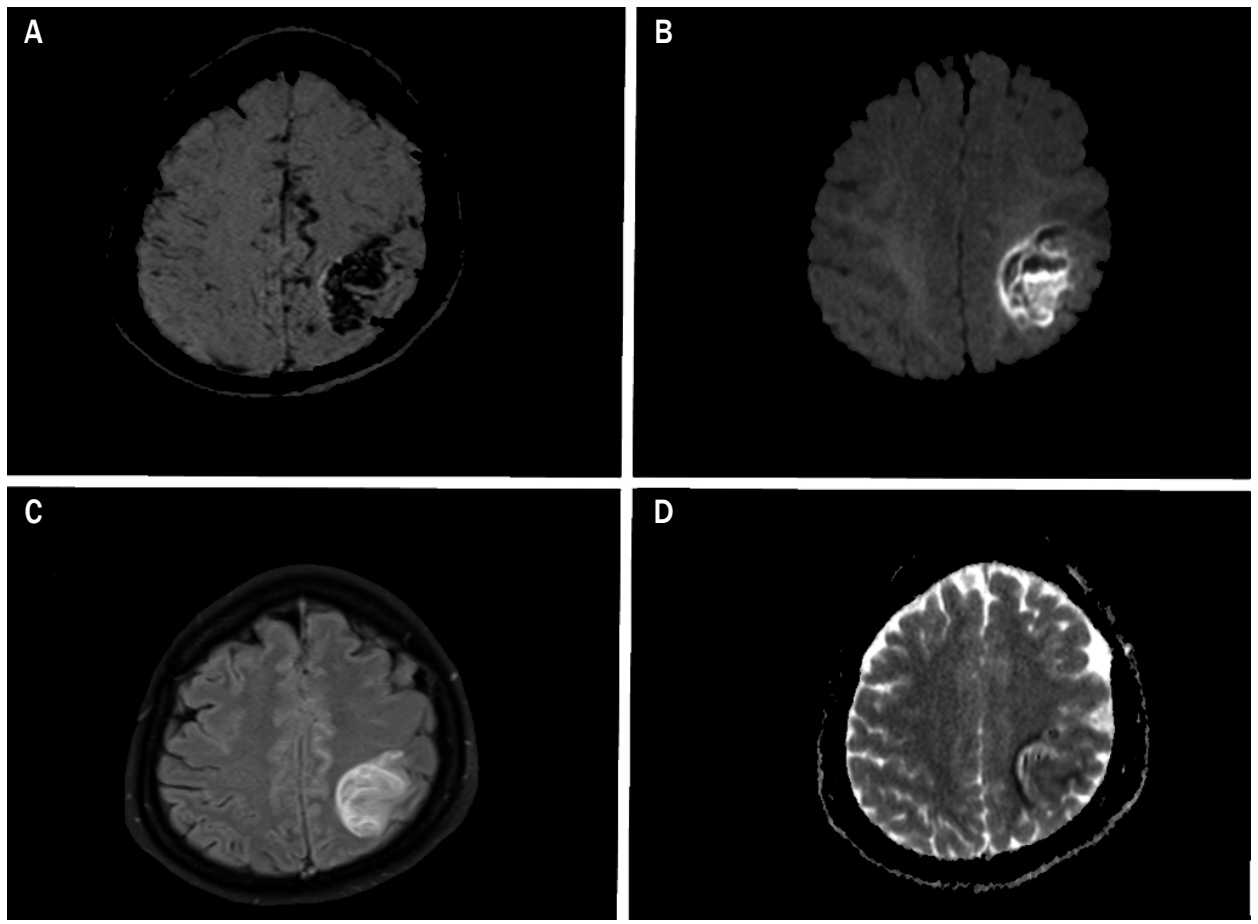

Figure 2. MRI of acute intracerebral haemorrhage of left brain hemisphere due to CVST. A. Susceptibility weight imaging. B. Diffusion weight imaging. C. Fluid-attenuated inversion recovery imaging. D. Apparent diffusion coefficient technique

Table 2. Clinical features of patients with CVST

\begin{tabular}{|c|c|c|c|c|}
\hline $\begin{array}{l}\text { Time from } \\
\text { symptoms } \\
\text { onset, days }\end{array}$ & Symptoms on onset & Other symptoms and signs & Complications & Prior risk factors \\
\hline 6 & Headache & - & - & Oral contraception \\
\hline 4 & Headache, nausea & - & - & - \\
\hline Not known & Coma & Coma & Stroke, pneumonia & Infection, cachexia \\
\hline 1 & Headache, nausea, vertigo & Nystagmus, vomiting & - & Oral contraception \\
\hline 3 & Headache, nausea & Vomiting & - & Otitis media, sinusitis \\
\hline 6 & Headache, nausea & Vomiting & - & Oral contraception, mastoiditis \\
\hline 10 & Headache & Left face hypoesthesia & - & - \\
\hline 3 & Headache, vertigo, nausea & $\begin{array}{l}\text { Vomiting, positive Romberg test, } \\
\text { cerebellar gait }\end{array}$ & $\begin{array}{c}\text { Seizure, } \\
\text { SAH }\end{array}$ & - \\
\hline 3 & Headache, nausea, vertigo & Vomiting & - & Oral contraception, sinusitis \\
\hline 3 & Headache & Vomiting & - & - \\
\hline 7 & Headache & - & - & Otitis media, sinusitis \\
\hline 1 & - & Aphasia, right hemiparesis & $\begin{array}{l}\text { Seizure, haemorrhagic } \\
\text { stroke }\end{array}$ & Postpartum period \\
\hline Not known & Asymptomatic & - & - & Smoking \\
\hline 4 & Headache & - & Ischaemic stroke, SAH & $\begin{array}{l}\text { Oral contraception, smoking, } \\
\text { obesity }\end{array}$ \\
\hline 7 & Headache & - & SAH & Oral contraception \\
\hline 1 & Headache & Aphasia, right hemiparesis & Ischaemic stroke & Oral contraception, obesity \\
\hline 3 & Headache & Left hemianesthesia & - & Ischaemic stroke \\
\hline 3 & Headache & - & - & - \\
\hline 60 & Headache & - & - & Otitis media \\
\hline 7 & Headache & - & - & $\begin{array}{l}\text { Raynaud disease, Hyperhomocys- } \\
\text { teinemia }\end{array}$ \\
\hline
\end{tabular}


Table 3. Clinical data of control group (patients with diagnosis of primary headache)

\begin{tabular}{|c|c|c|c|c|c|c|c|}
\hline Sex & Age & Type of headache & D-dimer. ug/ml & CRP. $\mathrm{mg} / \mathrm{l}$ & $\begin{array}{l}\text { Normal vascular } \\
\text { brain imaging }\end{array}$ & $\begin{array}{l}\text { Time from } \\
\text { symptoms on- } \\
\text { set (days) }\end{array}$ & $\begin{array}{l}\text { Important concomi- } \\
\text { tant disorders }\end{array}$ \\
\hline $\mathrm{F}$ & 25 & Tension type & 1.66 & 38.9 & Angio-CT & 28 & Urinary tract infection \\
\hline $\mathrm{F}$ & 45 & Migraine & 0.64 & 1.0 & Angio-CT & 7 & Urinary tract infection \\
\hline $\mathrm{F}$ & 25 & Tension type & 0.32 & 1.0 & Angio-MR & 1 & \\
\hline$M$ & 79 & Tension type & 0.86 & 3.2 & Angio-MR & $>365$ & Urinary tract infection \\
\hline$M$ & 35 & Tension type & 0.25 & 1.0 & Angio-MR & 9 & \\
\hline $\mathrm{F}$ & 36 & Tension type & 0.19 & 1.0 & Angio-CT & 60 & \\
\hline $\mathrm{F}$ & 19 & Tension type & 0.15 & 0.3 & Angio-MR & 7 & \\
\hline$M$ & 41 & Tension type & 0.15 & 2.2 & Angio-CT & 3 & \\
\hline $\mathrm{F}$ & 42 & Tension type & 0.17 & 0.2 & Angio-MR & 21 & \\
\hline$M$ & 41 & Tension type & 0.43 & 1.0 & Angio-CT & 21 & \\
\hline M & 59 & Tension type & 0.69 & 1.0 & Angio-CT & 28 & Prostate cancer \\
\hline $\mathrm{F}$ & 48 & Migraine & 0.29 & 0.2 & Angio-MR & 21 & \\
\hline $\mathrm{F}$ & 39 & Migraine & 0.40 & 2.8 & Angio-CT & 1 & \\
\hline $\mathrm{F}$ & 39 & Tension type & 0.23 & 1.0 & Angio-CT & 60 & \\
\hline $\mathrm{F}$ & 35 & Migraine & 0.16 & 0.2 & Angio-CT & 1 & \\
\hline $\mathrm{F}$ & 63 & Tension type & 0.22 & 1.2 & Angio-CT & 90 & \\
\hline $\mathrm{F}$ & 46 & Migraine & 1.05 & 13.8 & Angio-CT & 2 & Urinary tract infection \\
\hline $\mathrm{F}$ & 25 & Tension type & 0.31 & 1.6 & Angio-MR & 4 & \\
\hline M & 24 & Tension type & 0.47 & 62.9 & Angio-CT & 90 & \\
\hline $\mathrm{F}$ & 54 & Migraine & 0.52 & 1.3 & Angio-CT & 2 & \\
\hline $\mathrm{F}$ & 30 & Tension type & 1.73 & 1.4 & Angio-MR & 5 & Pregnancy \\
\hline $\mathrm{F}$ & 31 & Tension type & 0.21 & 0.4 & Angio-CT & 7 & \\
\hline
\end{tabular}

CRP - C-reactive protein; $\mathrm{CT}$ - computed tomography; $\mathrm{F}$ - female; $\mathrm{M}$ - male; $\mathrm{MR}$ - magnetic resonance

might correlate with greater thrombus extension and acute onset of symptoms.

In the study by Hiltunen et al., 71 patients included had a median level of DD of $1.40 \mathrm{mg} / \mathrm{L}$ (range $0.05-13.0 \mathrm{mg} / \mathrm{L}$ ). In nine (12\%) patients DD was low, and of these seven presented with subacute and two with chronic mode of symptom duration. Elevated DD levels were associated with thrombosis in multiple sinuses $(p=0.044)$. Longer symptom duration has been correlated with low D-dimer levels $(\mathrm{p}=0.010)$ [10]. Unfortunately, we did not confirm this in our preliminary study.

Venography may be beneficial in diagnosing CVST in ambiguous patients with higher levels of DD. Clinically useful biomarkers (such as DD) may predict CVST in the emergency department in ambiguous patients with or without unequivocal MRI/MRV imaging. A higher DD level might help to decide whether venography is indicated in patients with headache as the only symptom.

CVST symptoms can overlap in many ways with other neurological disorders. However, in the study by Meng et al.

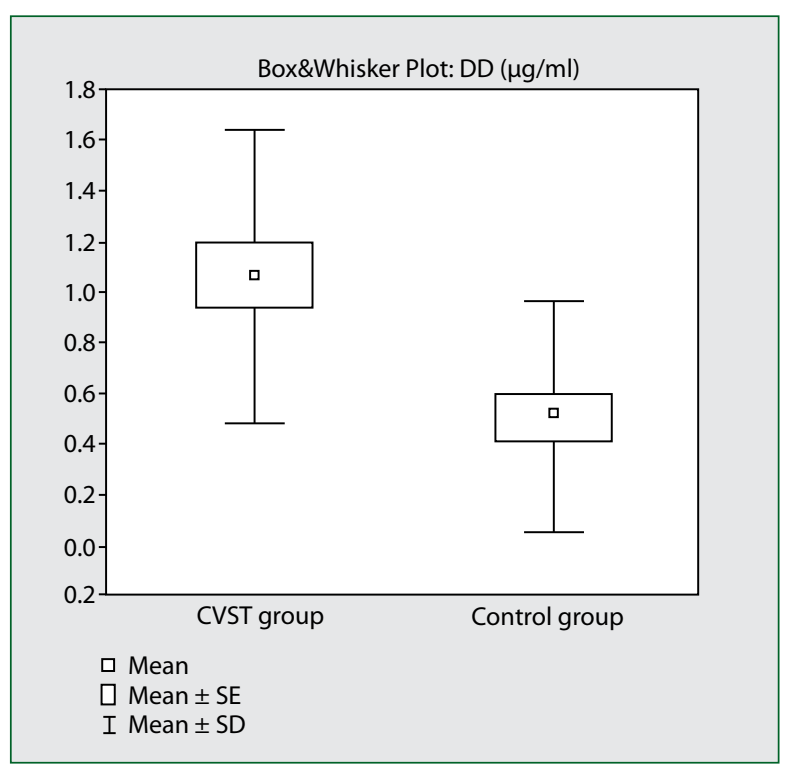

Figure 3. D-dimer concentrations in study groups 
[17], more than $20 \%$ of CVST occurred without a definitive medical history, and more than $70 \%$ of CVST occurred without focal neurological deficits. In the acute phase of CVST, DD (and additionally fibrinogen) were found to be abnormally elevated in $94.1 \%$ and $73.5 \%$ of cases, respectively. In the CVST group, the predominant features in MRI/MRV and DSA imaging included focal brain lesions, flow void signal loss, non-visualisation, and a local filling defect sign at the involved sinus [17].

We agree with Gunes et al. [18], who concluded that the differential diagnosis of CVST should be always borne in mind in patients with a sudden, new or worsening headache, especially (but not only) in those at high risk of thrombosis [19].

It is important to note that in clinical practice low levels of DD cannot rule out CVST in patients with subacute or chronic disease. In many cases, high DD levels correlate with the acute onset of symptoms [10]. Thus, a higher DD level may be a predictive factor for CVST. But on the other hand, a normal concentration of D-dimer does not release us from performing more diagnostic tests to exclude CVST, as this cause of headache is potentially dangerous for the patient.

Acknowledgments: This study received no specific grant from any agency in the public, commercial or not-for profit sectors. Ethical standards: All procedures performed in studies involving human participants were in accordance with the ethical standards of the institutional and/or national research committee and with the 1964 Helsinki Declaration and its later amendments or comparable ethical standards.

\section{References}

1. Hinnell C, Nadeau J, Lam V, et al. Sex differences in adult cerebral venous sinus thrombosis: a 10-year experience. Can J Neurol Sci. 2012; 39(1): 74-77, doi: 10.1017/s0317167100012725, indexed in Pubmed: 22384499.

2. Park JK, Koo DoH, Yoon DH, et al. D-Dimer Levels and Vitamin $\mathrm{K}$ Antagonist Therapy in Deep Vein Thrombosis of the Legs. Ann Vasc Surg. 2016; 34: 119-134, doi: 10.1016/j.avsg.2015.11.038, indexed in Pubmed: 27177705.

3. Cushman M, Folsom AR, Wang Lu, et al. Fibrin fragment D-dimer and the risk of future venous thrombosis. Blood. 2003; 101(4): 1243-1248, doi: 10.1182/blood-2002-05-1416, indexed in Pubmed: 12393393.

4. Skoro-Sajer N, Gerges C, Gerges M, et al. Usefulness of thrombosis and inflammation biomarkers in chronic thromboembolic pulmonary hypertension-sampling plasma and surgical specimens. J Heart Lung Transplant. 2018; 37(9): 1067-1074, doi: 10.1016/j. healun.2018.04.003, indexed in Pubmed: 29802084.
5. Takach Lapner S, Stevens SM, Woller SC, et al. Age-adjusted versus clinical probability-adjusted D-dimer to exclude pulmonary embolism. Thromb Res. 2018; 167: 15-19, doi: 10.1016/j. thromres.2018.05.003, indexed in Pubmed: 29753834.

6. Singer AJ, Zheng H, Francis S, et al. D-dimer levels in VTE patients with distal and proximal clots. Am J Emerg Med. 2019; 37(1): 33-37, doi: 10.1016/j.ajem.2018.04.040, indexed in Pubmed: 29703562.

7. Cushman M, Folsom AR, Wang Lu, et al. Fibrin fragment D-dimer and the risk of future venous thrombosis. Blood. 2003; 101(4): 1243-1248, doi: 10.1182/blood-2002-05-1416, indexed in Pubmed: 12393393.

8. Kuwashiro $\mathrm{T}$, Toyoda $\mathrm{K}$, Oyama N, et al. High plasma D-dimer is a marker of deep vein thrombosis in acute stroke. J Stroke Cerebrovasc Dis. 2012; 21(3): 205-209, doi: 10.1016/j.jstrokecerebrovasdis.2010.06.009, indexed in Pubmed: 20813546.

9. Wang HF, Pu CQ, Yin Xi, et al. D-dimers (DD) in CVST. Int J Neurosci. 2017; 127(6): 524-530, doi: 10.1080/00207454.2016.1207172, indexed in Pubmed: 27426719.

10. Zuurbier SM, Hiltunen S, Lindgren E, et al. D-dimer and clinicoradiologic features in cerebral venous thrombosis. J Neurol Sci. 2013; 327(12): 12-14, doi: 10.1016/j.jns.2013.01.033, indexed in Pubmed: 23434247.

11. Misra UK, Kalita J, Bansal V. D-dimer is useful in the diagnosis of cortical venous sinus thrombosis. Neurol India. 2009; 57(1): 50-54, doi: 10.4103/0028-3886.48822, indexed in Pubmed: 19305077.

12. Meng $R$, Wang $X$, Hussain $M$, et al. Evaluation of plasma D-dimer plus fibrinogen in predicting acute CVST. Int J Stroke. 2014; 9(2): 166-173, doi: 10.1111/ijs.12034, indexed in Pubmed: 23506130.

13. Stam J. Thrombosis of the cerebral veins and sinuses. N Engl J Med. 2005; 352: 1791-1798.

14. Filippidis A, Kapsalaki E, Patramani G, et al. Cerebral venous sinus thrombosis: review of the demographics, pathophysiology, current diagnosis, and treatment. Neurosurg Focus. 2009; 27(5): E3, doi: 10.3171/2009.8.FOCUS09167, indexed in Pubmed: 19877794.

15. Ferro JM, Canha P, Stam J, et al. Prognosis of cerebral vein and dural sinus thrombosis: results of international study on cerebral vein and dural sinus thrombosis (ISCVT). Stroke. 2004; 35: 664-670.

16. Gameiro J, Ferro JM, Canhão P, et al. International Study on Cerebral Vein and Dural Sinus Thrombosis investigators. Prognosis of cerebral vein thrombosis presenting as isolated headache: early vs. late diagnosis. Cephalalgia. 2012; 32(5): 407-412, doi: 10.1177/0333102412439353, indexed in Pubmed: 22407654.

17. Meng R, Dornbos D, Meng Lu, et al. Clinical differences between acute CVST and non-thrombotic CVSS. Clin Neurol Neurosurg. 2012; 114(9): 1257-1262, doi: 10.1016/j.clineuro.2012.03.036, indexed in Pubmed: 22676956.

18. Gunes HN, Cokal BG, Guler SK, et al. Clinical associations, biological risk factors and outcomes of cerebral venous sinus thrombosis. J Int Med Res. 2016; 44(6): 1454-1461, doi: 10.1177/0300060516664807, indexed in Pubmed: 28222615.

19. Wasay M, Kojan S, Dai Al, et al. Headache in Cerebral Venous Thrombosis: incidence, pattern and location in 200 consecutive patients. $J$ Headache Pain. 2010; 11(2): 137-139, doi: 10.1007/s10194-0100186-3, indexed in Pubmed: 20112042. 